\title{
Evaluation of protocols to synchronize estrus and ovulation in seasonal calving pasture-based dairy production systems
}

\author{
M. M. Herlihy, ${ }^{\star} †$ D. P. Berry, ${ }^{*}$ M. A. Crowe, $†$ M. G. Diskin, $\neq$ and S. T. Butler ${ }^{\star 1}$ \\ *Teagasc, Animal and Grassland Research and Innovation Centre, Moorepark, Fermoy, Co. Cork, Ireland \\ †School of Agriculture, Food Science and Veterinary Medicine, University College Dublin, Belfield, Dublin 4, Ireland \\ ¥Teagasc, Animal and Grassland Research and Innovation Centre, Mellows Campus, Athenry, Co. Galway, Ireland
}

\section{ABSTRACT}

Lactating dairy cows $(\mathrm{n}=1,538)$ were enrolled in a randomized complete block design study to evaluate protocols to synchronize estrus and ovulation. Within each herd $(\mathrm{n}=8)$, cows were divided into 3 calving groups: early, mid, and late, based on days in milk (DIM) at mating start date (MSD). Early calving cows $(\mathrm{n}=1,244)$ were $\geq 42$ DIM at MSD, mid-calving cows $(\mathrm{n}=179)$ were 21 to 41 DIM at MSD, and latecalving cows $(\mathrm{n}=115)$ were 0 to 20 DIM at MSD. Cows in the early, mid-, and late-calving groups were synchronized to facilitate estrus or timed AI (TAI) at MSD (planned breeding 1; PB1), $21 \mathrm{~d}$ (PB2), and 42 d (PB3) after MSD, respectively. For each PB, cows in the relevant calving group were stratified by parity and calving date and randomly assigned to 1 of 4 experimental groups: (1) d $-10 \mathrm{GnRH}(10 \mu \mathrm{g}$ of i.m. buserelin) and controlled internal drug release insert (CIDR; $1.38 \mathrm{~g}$ of progesterone); $\mathrm{d}-3 \mathrm{PGF}_{2 \alpha}(25 \mathrm{mg}$ of i.m. dinoprost); and $\mathrm{d}-2$ CIDR out and AI at observed estrus (CIDR_OBS); (2) same as CIDR_OBS, but GnRH $36 \mathrm{~h}$ after CIDR out and TAI $18 \mathrm{~h}$ later (CIDR_TAI); (3) same as CIDR_TAI, but no CIDR (Ovsynch); or (4) untreated controls (CTRL). The CIDR_OBS, CIDR_TAI, and Ovsynch had shorter mean intervals from calving to first service compared with the CTRL (69.2, 63.4, and 63.7 vs. $73.7 \mathrm{~d}$, respectively). Both CIDR_OBS (predicted probability; PP of pregnancy $=0.59$ ) and CIDR_TAI (PP of pregnancy $=0.54)$ had increased odds of conceiving at first service compared with Ovsynch $[\mathrm{PP}$ of pregnancy $=0.45$; odds ratio $(\mathrm{OR})=1.81$ and $\mathrm{OR}=1.46$, respectively], and Ovsynch had decreased likelihood of conceiving at first service $(\mathrm{OR}=0.70)$ compared with CTRL (PP of pregnancy $=0.53)$. Both CIDR_TAI \{hazard ratio; HR $[95 \%$ confidence interval $=1.21(1.04,1.41)]\}$ and Ovsynch $[\mathrm{HR}(95 \%$ confidence interval $)=1.23(1.05$, 1.44)] were associated with an increased likelihood of

Received December 23, 2010.

Accepted May 18, 2011.

${ }^{1}$ Corresponding author: Stephen.Butler@teagasc.ie earlier conception compared with the CTRL. A greater proportion of cows on the CIDR_TAI treatment successfully established pregnancy in the first $42 \mathrm{~d}$ of the breeding season compared with the CTRL (0.75 vs. 0.67 PP of 42-d pregnancy, respectively). Protocols to synchronize estrus and ovulation were effective at achieving earlier first service and conception in pasturebased seasonal calving dairy herds. However, animals that conceived following insemination at observed estrus had a decreased likelihood of embryo loss to first service compared with animals bred with TAI (PP of embryo loss after first service $=0.05$ vs. 0.09 ; OR $=$ $0.52)$.

Key words: estrous synchronization, Ovsynch, dairy cow, seasonal calving

\section{INTRODUCTION}

Milk production in seasonal calving pasture-based systems (e.g., such as in Ireland) is dependent on the efficient conversion of grazed grass into milk (Dillon et al., 1995). Compact calving before turnout to pasture in spring is an essential component of pasture-based milk production systems to ensure maximum pasture utilization and, hence, profitability (Dillon et al., 1995). Achieving a highly concentrated period of calving in the spring requires a high pregnancy rate within a short period following the planned start of mating. Cows with North American genetics produced well in pasturebased systems of milk production (Horan et al., 2005a), but reproductive performance of such cows was well below optimum for seasonal calving systems (Horan et al., 2005b). Aggressive single-trait selection for increased milk production in Irish seasonal calving herds decreased profitability because the productivity gains were outweighed by increases in the costs associated with reproductive wastage (McCarthy et al., 2007).

Maximizing the proportion of cows that establish pregnancy within the first $42 \mathrm{~d}$ of the breeding season decreases the incidence of extended calving patterns (McDougall, 2006). Later-calving cows with an extended postpartum anestrous interval can disrupt the seasonal calving pattern and result in extended calving patterns 
(Rhodes et al., 2003). Monitoring of submission rates in seasonal-calving dairy herds provides a reliable indication of the efficiency and accuracy of estrous detection (Diskin and Sreenan, 2000). Low submission rates decrease the proportion of animals becoming pregnant within the pre-defined 42-d period, thus negatively affecting the profitability of seasonal calving systems. Decreased profitability arises from mean calving date (MCD) occurring later in the year than optimal, and consequently, results in a less compact calving pattern. A study conducted in 74 Irish spring-calving dairy herds $(\mathrm{n}=6,433$ cows $)$ reported that $81 \%$ of cows were detected in estrus and inseminated within the first 3 wk of the breeding season, $49 \%$ of cows conceived at first insemination, and $57 \%$ of cows were pregnant by $42 \mathrm{~d}$ after the start of the breeding season (Buckley et al., 2003).

Traditional estrous synchronization programs using GnRH, progesterone (P4) and $\mathrm{PGF}_{2 \alpha}$ successfully synchronized estrus and resulted in earlier conception in seasonal calving systems (Ryan et al., 1995; Ryan et al., 1999; Xu and Burton, 2000). Ovulation synchronization protocols using timed AI (TAI) ensure that a cow is submitted for AI without the requirement to observe for signs of estrus. The Ovsynch protocol includes an injection of GnRH $7 \mathrm{~d}$ before and $2 \mathrm{~d}$ after an injection of $\mathrm{PGF}_{2 \alpha}$, with TAI occurring between 16 to $18 \mathrm{~h}$ after the second GnRH injection (Pursley et al., 1995). Successful use of Ovsynch involves (1) synchronizing the growth of a new follicular wave; (2) induced luteal regression 7 $\mathrm{d}$ later; and (3) synchronization of ovulation $2 \mathrm{~d}$ later. Improved pregnancy outcomes following Ovsynch were reported when an intravaginal P4 insert was included during the treatment protocol for anovular cows (Stevenson et al., 2008; Chebel et al., 2010; McDougall, 2010) and cows with high P4 at the time of controlled internal drug release (CIDR) insertion that were more likely to undergo spontaneous corpus luteum regression before $\mathrm{PGF}_{2 \alpha}$ (Bartolome et al., 2009). The objective of this study was to examine the potential effect on calving pattern and MCD through aggressive wholeherd intervention with protocols to synchronize estrus or ovulation. The results will be useful in benchmarking the effects of whole-herd synchronization treatments in seasonal-calving dairy production systems. This will be particularly useful for herds where MCD is currently later than desired.

\section{MATERIALS AND METHODS}

\section{Farms and Animals}

This study was conducted using 1,639 cows in 8 Irish commercial spring-calving dairy herds between April and June 2008. Within each farm, cows were managed as a single grazing herd and allocated fresh pasture twice daily as part of an intensively managed rotational grazing system with little or no concentrate supplementation. Breed compositions of the cows enrolled in the study comprised Holstein-Friesian $(\mathrm{n}=1,173)$, Jersey $\times$ Holstein-Friesian crossbreds $(\mathrm{n}=284)$, Norwegian Red $(\mathrm{n}=16)$, Norwegian Red $\times$ Holstein-Friesian crossbreds $(\mathrm{n}=25)$, and other $(\mathrm{n}=141)$. The distribution of breeds on individual farms ranged from primarily Holstein-Friesian to primarily crossbreds. All experimental procedures involving animals were licensed in accordance with the Cruelty to Animals Act (Ireland 1876) and the European Community Directive 86/609/ EC and were sanctioned by the University College Dublin Animal Research Ethics Committee. A clinical trials license was awarded by the Department of Agriculture, Fisheries and Food (Ireland) following approval by the Irish Medicines Board for the use of CIDR devices (1.38 $\mathrm{g}$ of $\mathrm{P} 4)$ that were undergoing registration approval at the time of the experiment.

\section{Experimental Design and Treatments}

All 1,639 lactating dairy cows were used in a completely randomized block experimental design to evaluate synchronization protocols. Within each herd, cows were divided into 3 groups: early, mid, and late calving based on DIM at the farm mating start date (MSD). Early calving cows $(\mathrm{n}=1,301)$ were $\geq 42$ DIM at MSD, mid-calving cows $(\mathrm{n}=212)$ were 21 to 41 DIM at MSD, and late-calving cows $(\mathrm{n}=126)$ were 0 to 20 DIM at MSD. Synchronization treatments commenced 10 $\mathrm{d}$ before MSD for the early calving cows, facilitating estrus or TAI at MSD (planned breeding 1; PB1) as illustrated in Figure 1, upper panel. All early calving cows were $\geq 42$ DIM at AI (range in DIM of 42 to 105). Synchronization treatments commenced on d 11 and 32 after MSD for the mid- and late-calving cows, respectively. The treatments facilitated estrus or TAI 21 $\mathrm{d}$ after MSD (PB2) and $42 \mathrm{~d}$ after MSD (PB3) for the mid- and late-calving cows, respectively. All mid- and late-calving cows were between 42 and 62 DIM at AI. Thus, the experimental treatments were imposed on all cows that had calved up to and including MSD.

\section{Synchronization Treatments and AI}

Within each calving group, cows were stratified by parity and DIM and randomly assigned to 1 of the 4 treatments illustrated in Figure 1, lower panel. The CIDR_OBS treatment was an estrous-synchronization protocol, whereas CIDR_TAI and Ovsynch were ovulation-synchronization protocols. The synchroniza- 

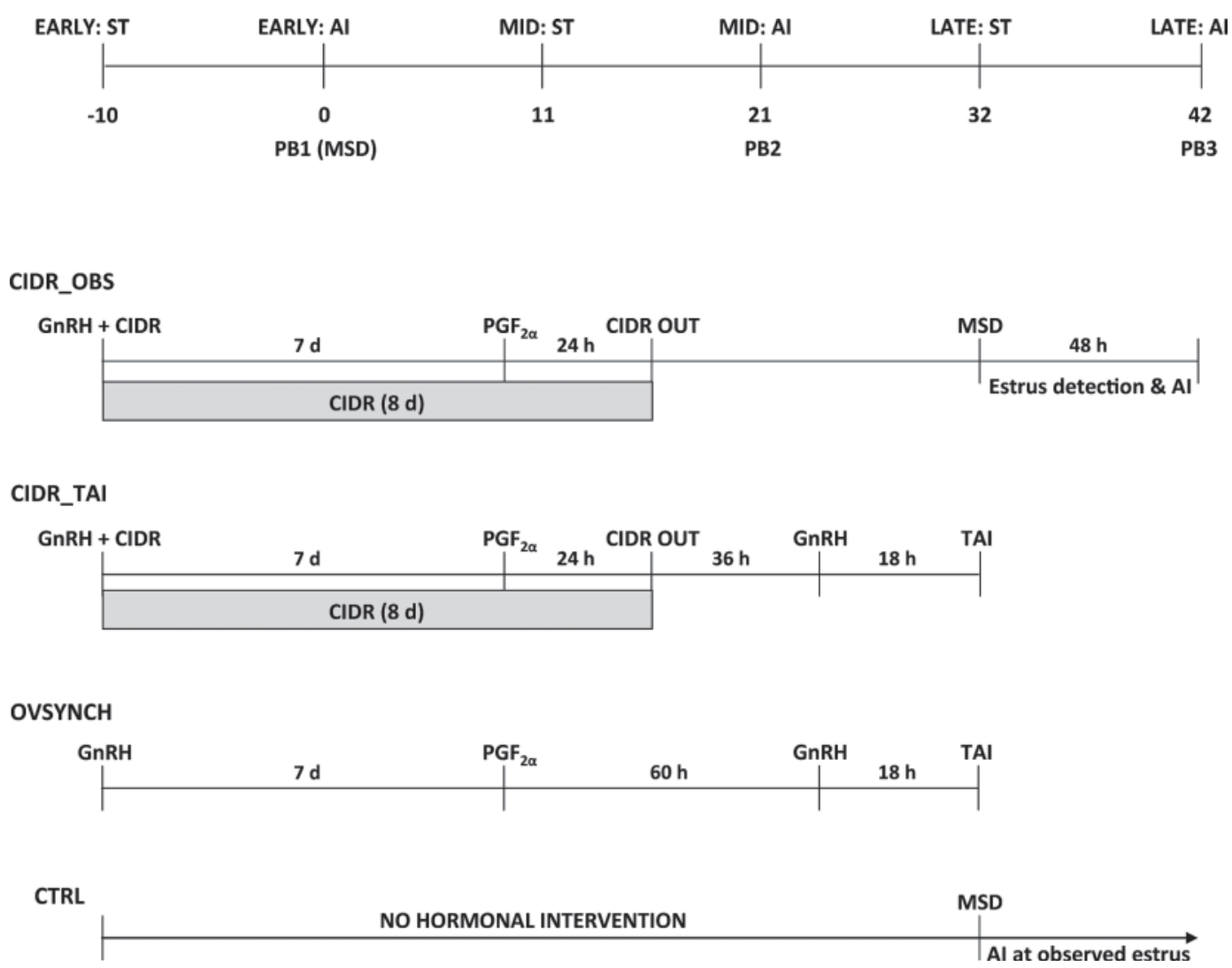

Figure 1. Schematic diagram of experimental design used to evaluate synchronization treatments (ST; upper panel) and treatment protocols to synchronize estrus and ovulation (lower panel). Early calving cows were $\geq 42$ DIM at the mating start date (MSD), mid-calving cows were 21 to 41 DIM at the MSD, and late-calving cows were 0 to 20 DIM at the MSD. PB1, PB2, and PB3 = planned breeding 1 (MSD), 2, and 3, respectively. $\mathrm{CIDR}=$ controlled internal drug release; $\mathrm{OBS}=$ observed estrus; TAI $=$ timed AI; CTRL $=$ control. For each seasonal-calving farm in the study $(\mathrm{n}=8)$, breeding started on a fixed MSD. In this study, PB1 coincided with the MSD for each farm, PB2 occurred 21 d after PB1, and PB3 occurred $42 \mathrm{~d}$ after PB1 or $21 \mathrm{~d}$ after PB2. Treatment protocols for synchronization were initiated at a random stage of the estrous cycle and applied to lactating dairy cows before the first service. CIDR_OBS $=10 \mu \mathrm{g}$ of GnRH and CIDR insert at d 0, $25 \mathrm{mg}$ of PGF $2 \alpha$ at $\mathrm{d}$ 7, CIDR removed at d 8; animals were inseminated by the a.m./p.m. rule, following detection of estrus on d 10, 11, and 12 . CIDR_TAI $=10 \mu \mathrm{g}$ of GnRH and CIDR insert at d 0, $25 \mathrm{mg}$ of $\mathrm{PGF}_{2 \alpha}$ at $\mathrm{d}$ 7, CIDR removed at d 8, $10 \mu \mathrm{g}$ of $\mathrm{GnRH} 60 \mathrm{~h}$ after PGF $2 \alpha$ or $36 \mathrm{~h}$ after CIDR removal;

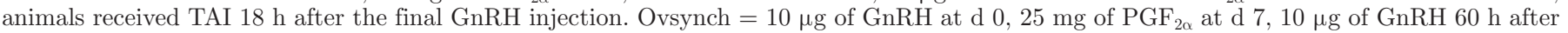
$\mathrm{PGF}_{2 \alpha} ;$ animals received TAI $18 \mathrm{~h}$ after the final $\mathrm{GnRH}$ injection.

tion protocols were initiated at a random stage of the estrous cycle. Cows assigned to the control (CTRL) treatment $(\mathrm{n}=400)$ received no hormonal interventions. The i.m. GnRH agonist injections contained 10 $\mu \mathrm{g}$ of buserelin (Receptal; Intervet Ireland Ltd., Dublin, Ireland). The CIDR device used contained $1.38 \mathrm{~g}$ of P4 (Pfizer Ireland, Dublin, Ireland). The i.m. $\mathrm{PGF}_{2 \alpha}$ contained $25 \mathrm{mg}$ of dinoprost tromethamine (Lutalyse; Pfizer Ireland). All hormonal treatments were administered by research staff from Teagasc Moorepark (Fermoy, Co. Cork, Ireland). Cows assigned to CTRL and CIDR_OBS were inseminated by the a.m./p.m. rule, following detection of estrus with the aid of tail paint. All cows on the CIDR_TAI and Ovsynch protocols received TAI $18 \mathrm{~h}$ after the second GnRH injection. The second GnRH injection was administered $60 \mathrm{~h}$ after $\mathrm{PGF}_{2 \alpha}$, as animals were only available at milking times; therefore, GnRH was administered after the evening milking as animals exited the milking parlor. All inseminations were performed by experienced technicians from commercial AI companies or by the herd owners and farm staff licensed by the Department of Agriculture, Fisheries and Food (Ireland) to carry out AI.

\section{Transrectal Ultrasonography}

The reproductive tracts of all cows were examined immediately before initiation of synchronization treatments by linear array ultrasonography using a $5.0-\mathrm{MHz}$ transrectal transducer (Aloka SSD-500; Aloka Ltd., Tokyo, Japan). Cows were assigned an ultrasound reproductive tract score describing the volume and echogenicity of fluid contained within the uterus (Mee et. al., 2009). Cows that were classified as endometritic 
were not included in the study. To determine conception rates and embryo loss, all cows on synchronization treatments were scanned at 30 to $32 \mathrm{~d}$ and 56 to 58 d post-AI. For CTRL cows, the mean (and SD) days post-AI at the corresponding scans were $41.2(7.8)$ and 64.2 (6.2), respectively. Visualization of a fluid-filled uterine horn and the presence of a conceptus were used as positive indicators of pregnancy. For all cows in each herd, final pregnancy status was confirmed by palpation per rectum approximately 6 wk after the end of the breeding season.

\section{Blood Collection and Progesterone Radioimmunoassay}

Blood was collected in lithium heparin Vacutainer tubes (Becton Dickinson and Co., Plymouth, UK) by puncture of coccygeal vessels on the day of PB1 (early cows), PB2 (mid cows), and PB3 (late cows) and again $11 \mathrm{~d}$ after PB1, PB2, and PB3. Blood samples were immediately placed in ice, and were later centrifuged at $2,000 \times g$ for $15 \mathrm{~min}$ at $5^{\circ} \mathrm{C}$; the plasma was harvested and stored at $-20^{\circ} \mathrm{C}$ until later analysis. Concentrations of $\mathrm{P} 4$ in plasma were determined using a commercially available solid-phase radioimmunoassay (Coat-ACount Progesterone; Diagnostic Products Corp., Los Angeles, CA). Sensitivity of the assay was $0.08 \mathrm{ng} / \mathrm{mL}$; intra- and interassay coefficients of variation were 8.5 and $7.9 \%$, respectively.

\section{Reproductive Measurements}

The following reproductive measurements were calculated and analyzed: 5-d submission relative to PB1, PB2, PB3 (binary); 21-d submission relative to PB1, PB2, PB3 (binary); overall 21-d submission (i.e., inseminated or not inseminated within the first $21 \mathrm{~d}$ of the breeding season irrespective of calving date; binary); calving to first service interval (CSI; interval in days from calving to first service; continuous); mating start date to conception (MSDC; interval in days from the mating start to conception determined by subsequent pregnancy detection; continuous); conception at first service (confirmed pregnant by ultrasonography at 30 to $32 \mathrm{~d}$ after first AI; binary); conception at second service (confirmed pregnant by ultrasonography at 30 to $32 \mathrm{~d}$ after second AI; binary); embryonic loss after first service [loss of a viable pregnancy between pregnancy diagnosis 1 (d 30 to 32 post-AI) and pregnancy diagnosis 2 (d 56 to 58 post-AI; binary)]; and 42-d pregnancy rate (successfully established pregnancy during the first $42 \mathrm{~d}$ of the breeding season; binary). When an individual cow received more than 1 insemination within a 4-d period, it was defined as 1 heat event and the later insemination date was used in the analysis.

\section{Compliance to Protocol}

Initially, 1,639 animals were enrolled in the study. However, 101 animals were subsequently removed from the data set as they were not fully compliant with the designed protocol or were removed for other reasons described below. The breaches in protocol are illustrated in Figure 2, and included missed injections, mistimed CIDR removal, CIDR loss, and non-compliant inseminations. Animals considered unsuitable for breeding, determined by ultrasonography at the time of assignment to synchronization treatments were removed from the data set. Control animals administered injections were removed from the data set. Animals with a missing value for conception rate at first service were removed from the data set. After data edits, the final data set included 1,538 cows used in protocols to synchronize estrus and ovulation. The numbers of animals reported per treatment were as follows: CIDR_OBS $(\mathrm{n}=398)$, CIDR_TAI $(\mathrm{n}=383)$, Ovsynch $(\mathrm{n}=370)$, and CTRL $(\mathrm{n}=387)$. The numbers of animals in the 3 calving groups that received synchronization treatments were as follows: early $(\mathrm{n}=1,244)$, mid $(\mathrm{n}=179)$, and late $(\mathrm{n}=115)$.

\section{Synchronization Rate}

Cows were categorized according to plasma $\mathrm{P} 4$ at d 0 (presumptive estrus) and d 11 after insemination [high $(\mathbf{H} ; \geq 1 \mathrm{ng} / \mathrm{mL}) ;$ low $(\mathbf{L} ;<1 \mathrm{ng} / \mathrm{mL})]$. Cows were grouped into $\mathrm{P} 4$ classes, which resulted in 4 possible $\mathrm{P} 4$ class permutations for synchronized cows: HH, LL, HL, and LH. Only cows with L plasma P4 on d 0 and $\mathrm{H}$ plasma $\mathrm{P} 4$ on d 11 (i.e., LH) were considered synchronized. Of the 1,538 cows enrolled in the synchronization study, 1,506 (98\%) cows were classified into 1 of the 4 P4 classes; at least 1 blood sample was missed for the remaining $32(2 \%)$ cows. Progesterone concentrations in samples from CTRL cows were used to determine the proportion of CTRL cows that were cyclic/anestrous at each $\mathrm{PB}$.

\section{Statistical Analyses}

Binary Traits. The effect of synchronization treatment and calving group (i.e., early, mid, late) on the binary traits was determined using logistic regression with the GENMOD Procedure of SAS (SAS Institute Inc., Cary, NC). A logit link function was used and a binomial distribution was assumed. The 8 binary 


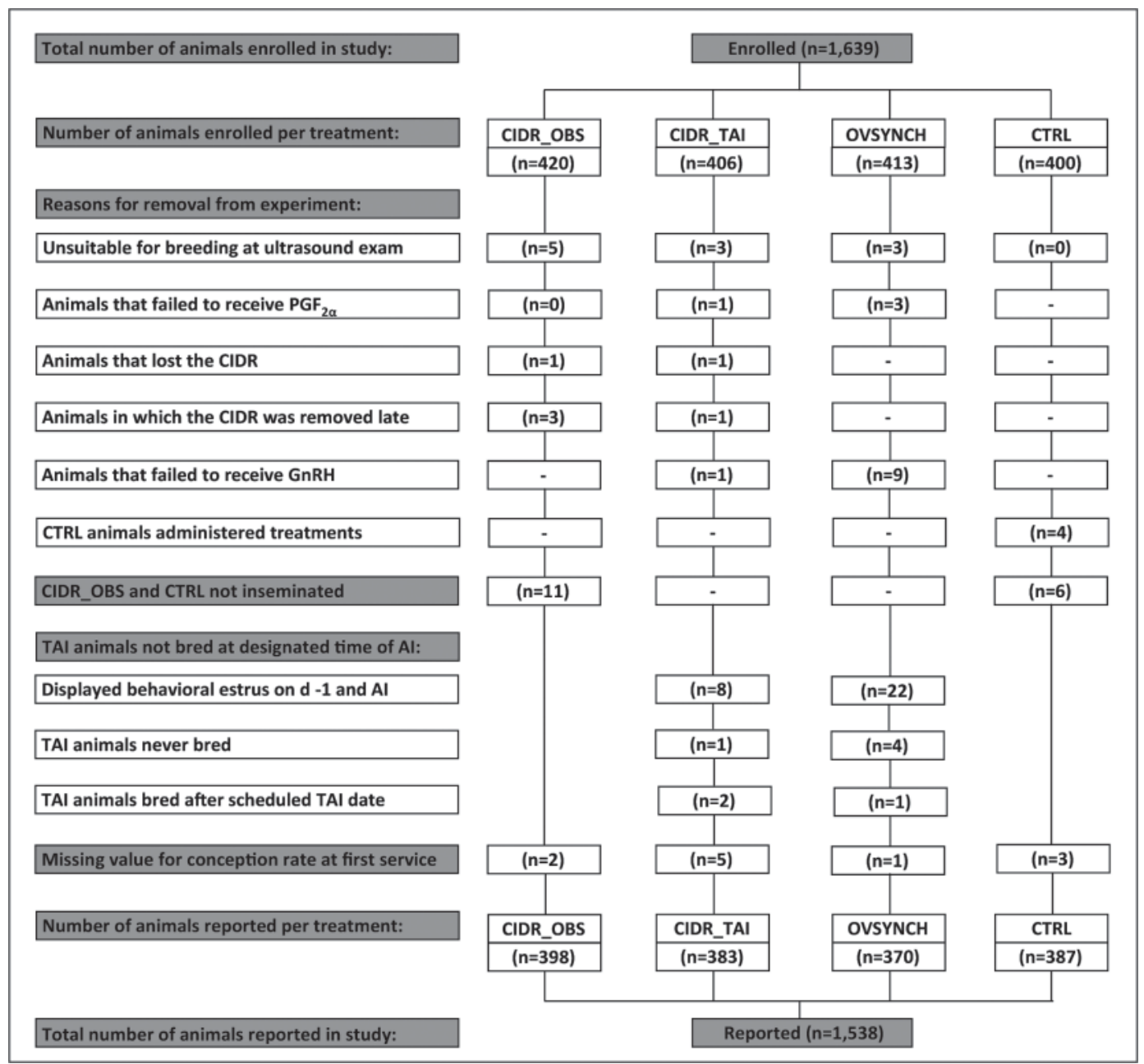

Figure 2. Flowchart showing assignment of animals to treatment protocols to synchronize estrus and ovulation. After data edits, the final data set included 1,538 cows used in protocols to synchronize estrus and ovulation. The numbers of animals in the 3 calving groups that received synchronization treatments were as follows: early calving (group $1 ; \mathrm{n}=1,244$ ), mid-calving (group 2; $\mathrm{n}=179$ ), and late-calving (group 3; $\mathrm{n}=$ 115). $\mathrm{CIDR}=$ controlled internal drug release; OBS $=$ observed estrus; TAI $=$ timed AI; CTRL $=$ control. CIDR_OBS $=10 \mu \mathrm{g}$ of GnRH and CIDR insert at d 0, $25 \mathrm{mg}$ of $\mathrm{PGF}_{2 \alpha}$ at d 7, CIDR removed at d 8; animals were inseminated by the a.m./p.m. rule, following detection of estrus on d 10, 11, and 12. CIDR_TAI $=10 \mu \mathrm{g}$ of GnRH and CIDR insert at d $0,25 \mathrm{mg}$ of PGF $\mathrm{P}_{2}$ at d 7 , CIDR removed at d $8,10 \mu \mathrm{g}$ of GnRH $60 \mathrm{~h}$ after $\mathrm{PGF}_{2 \alpha}$ or $36 \mathrm{~h}$ after CIDR removal; animals received TAI $18 \mathrm{~h}$ after the final GnRH injection. Ovsynch $=10 \mu \mathrm{g}$ of $\mathrm{GnRH}$ at $\mathrm{d} 0,25 \mathrm{mg}$ of $\mathrm{PGF}_{2 \alpha}$ at $\mathrm{d}$ 7, $10 \mu \mathrm{g}$ of $\mathrm{GnRH} 60 \mathrm{~h}$ after $\mathrm{PGF}_{2 \alpha}$; animals received TAI $18 \mathrm{~h}$ after the final $\mathrm{GnRH}$ injection.

traits were 5-d submission rate relative to each $\mathrm{PB}$, 21-d submission rate relative to each $\mathrm{PB}$, overall $21-\mathrm{d}$ submission rate, conception rate at first service, conception rate at second service, embryonic loss after first service, 42-d pregnancy rate, and synchronization rate. The logit of the probability of a positive outcome was modeled.

Model solutions were converted back to predicted probabilities by the formula

$$
P=\left(1+\mathrm{e}^{-(\alpha+\beta \mathbf{x})}\right)^{-1},
$$

where $\alpha$ is the predicted intercept of the model, $\beta$ is the predicted regression coefficient(s), and $\mathbf{x}$ is the design matrix for the fixed effects in the model. The intercept represented the average farm and was representative of the parity and calving date structure in the data. Predicted probabilities may be interpreted as least squares means for the variable of interest estimated using linear models.

Odds ratios (OR) were calculated as the exponent of the model solutions. The OR is an estimation of the relative odds of an event (i.e., likelihood of a positive outcome) occurring in the exposed group relative to a reference group or class. The CTRL synchronization treatment and the early calving group $(\geq 42$ DIM at MSD) were used as the reference groups for all variables with the exception of synchronization rate. For synchronization rate, CTRL animals were removed from the analysis and the Ovsynch synchronization 
treatment and the early calving group $(\geq 42$ DIM at MSD) were used as the reference groups. An OR of 1 represents an equal likelihood of an event occurring to an animal in a particular group compared with a contemporary in the reference group. An OR of $>1$ implies an increased likelihood of a positive outcome, whereas the opposite is true with an OR of $<1$.

Explanatory independent variables considered for inclusion in all models included treatment $(\mathrm{n}=4)$, farm $(\mathrm{n}=8)$, parity of the cow $(1,2,3,4$, and $\geq 5)$, calving group (i.e., early, mid, and late), breed fraction of the cow as continuous variables (Holstein-Friesian, Jersey, Norwegian Red, and other), heterosis and recombination loss coefficients of the cow as continuous variables, an interaction term between synchronization treatment and calving group, and an interaction term between synchronization treatment and parity. Breed fraction, recorded in increments of $1 / 32$, was fitted as a continuous variable to account for differences in the proportion of each breed (Holstein-Friesian, Jersey, Norwegian Red, and other) in an animal; each breed was fitted as a separate covariate. Factors not associated $(P>$ $0.05)$ with the dependent variables were removed by backward elimination. Preplanned contrasts were used to compare treatments to synchronize estrus and ovulation with the CTRL treatment.

Non-Binary Traits. The effect of synchronization treatment and calving group on CSI was determined using a fixed effects linear model in the GLM procedure of SAS (SAS Institute Inc.). Explanatory independent variables considered for inclusion in the model were as before and included treatment $(\mathrm{n}=4)$, farm $(\mathrm{n}=8)$, parity of the cow $(1,2,3,4$, and $\geq 5$ ), calving group (i.e., early, mid, and late), breed fraction of the cow as continuous variables (Holstein-Friesian, Jersey, Norwegian Red, and other), heterosis and recombination loss coefficients as continuous variables, an interaction term between synchronization treatment and calving group, and an interaction term between synchronization treatment and parity. Breed fraction, recorded in increments of $1 / 32$, was fitted as a continuous variable to account for differences in the proportion of each breed (Holstein-Friesian, Jersey, Norwegian Red, and other) in an animal; each breed was fitted as a separate effect in the model. Factors not associated $(P>0.05)$ with the dependent variables were removed by backward elimination.

Survival analysis was carried out using the Cox proportional hazard model in SAS (TPHREG procedure; SAS Institute Inc.) to investigate the effect of synchronization treatment and calving group (i.e., early, mid, and late) on MSDC. In the analysis of MSDC, if a cow did not conceive at an insemination occurring during a 13-wk period from MSD, the data was right-censored at the maximum permissible value of $91 \mathrm{~d}$ (i.e., 13 wk). Explanatory independent variables considered for inclusion in the models were as before and included treatment $(\mathrm{n}=4)$, farm $(\mathrm{n}=8)$, parity of the cow $(1$, $2,3,4$, and $\geq 5$ ), calving group (i.e., early, mid, and late), breed fraction of the cow as continuous variables (Holstein-Friesian, Jersey, Norwegian Red, and other), heterosis and recombination loss coefficients as continuous variables, an interaction term between synchronization treatment and calving group, and an interaction term between synchronization treatment and parity. Breed fraction, recorded in increments of $1 / 32$, was fitted as a continuous variable, separate for each breed, to account for differences in the proportion of each breed (Holstein-Friesian, Jersey, Norwegian Red, and other) in an animal. Factors not associated $(P>0.05)$ with the dependent variables were removed by backward elimination.

Survival was expressed as the relative hazard (hazard ratio; HR) of a cow conceiving at time (day) $t$, given that it had not conceived at day $t-1$ in the exposed group relative to the reference group. The CTRL synchronization treatment and the early calving group $(\geq 42$ DIM at MSD) were used as the reference groups. An HR of $>1$ indicated that a unit increase in the value of the independent variable was associated with an increased likelihood of earlier occurrence of the event of interest. Predetermined contrasts were used to compare treatments to synchronize estrus and ovulation with the CTRL treatment.

The MSDC was also evaluated by the LIFETEST procedure of SAS (SAS Institute Inc.) using KaplanMeier analysis to investigate the effect of treatment on days from start of breeding to conception. The data are presented graphically as survival distribution function by days after the planned start of mating for MSDC (Figure 3).

\section{RESULTS}

\section{Reproduction and Fertility Performance}

The explanatory independent variables included in the final model for CSI and MSDC were treatment, farm, parity, and calving group. The fixed effect of farm had a significant effect $(P<0.05)$ on synchronization rate and all fertility variables investigated, with the exception of conception rate at second service, embryo loss after first service, and 5-d submission rate relative to each PB. The fixed effect of parity had a significant effect $(P<0.05)$ on overall 21 -d submission rate, 42 -d pregnancy rate, CSI, MSDC, and synchronization rate and had no effect on the remaining fertility variables. With the exception of synchronization rate and CSI, 


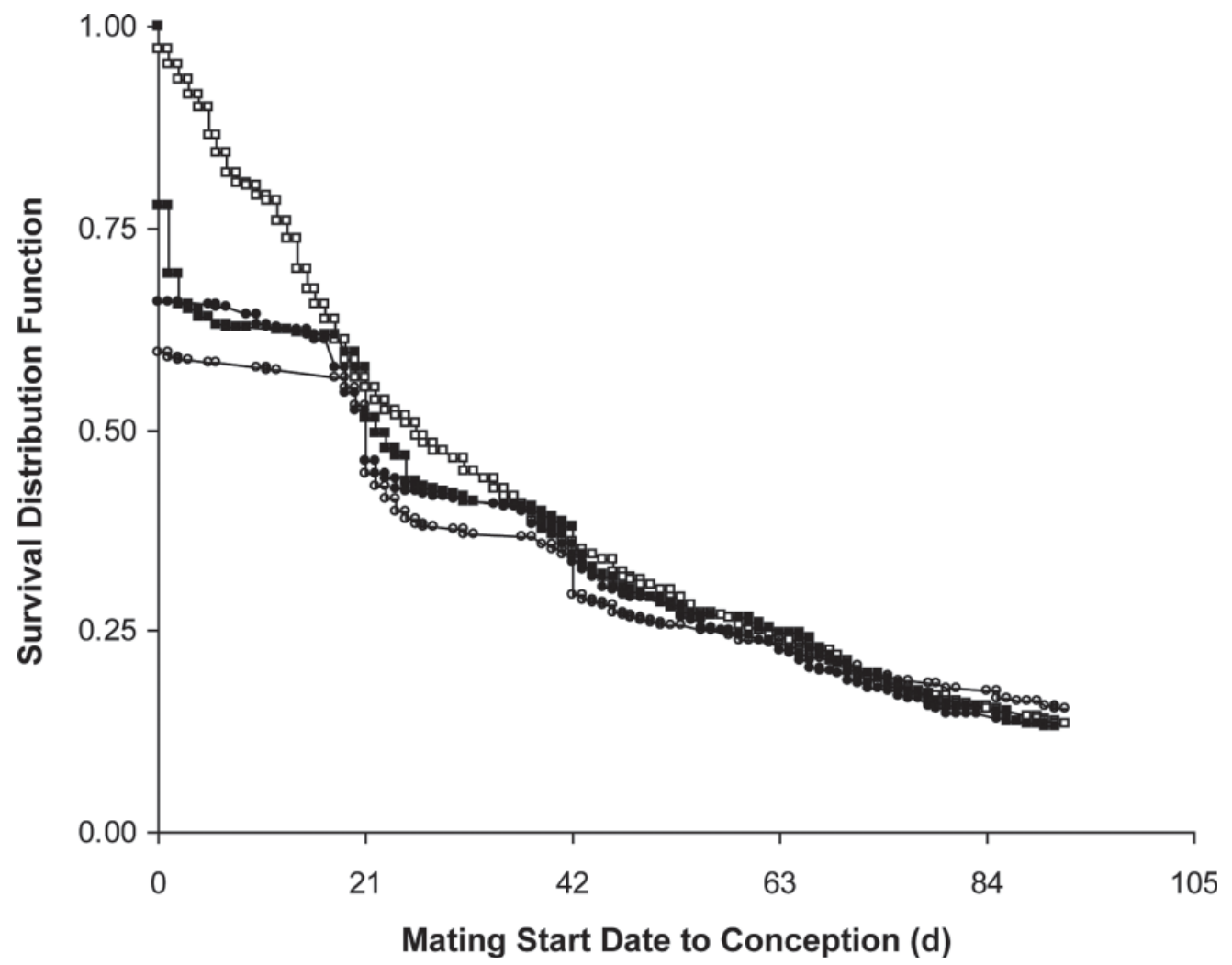

Figure 3. Survival distribution function for the interval in days from mating start date to conception (MSDC) for CIDR_OBS ( $\mathbf{\square})$, CIDR_ TAI (O), Ovsynch $(\bullet)$ and CTRL $(\square)$. CIDR = controlled internal drug release; OBS = observed estrus; TAI = timed AI; CTRL = control. CIDR_OBS $=10 \mu \mathrm{g}$ of GnRH and CIDR insert at d 0,25 mg of $\mathrm{PGF}_{2 \alpha}$ at d 7, CIDR removed at d 8; animals were inseminated by the a.m./p.m. rule, following detection of estrus on d 10, 11, and 12. CIDR_TAI $=10 \mu \mathrm{g}$ of GnRH and CIDR insert at d 0, $25 \mathrm{mg}$ of PGF $2 \alpha$ at d 7, CIDR removed at $\mathrm{d} 8,10 \mu \mathrm{g}$ of $\mathrm{GnRH} 60 \mathrm{~h}$ after $\mathrm{PGF}_{2 \alpha}$ or $36 \mathrm{~h}$ after CIDR removal; animals received TAI $18 \mathrm{~h}$ after the final GnRH injection. Ovsynch $=10 \mu \mathrm{g}$ of $\mathrm{GnRH}$ at $\mathrm{d}$ 0, $25 \mathrm{mg}$ of $\mathrm{PGF}_{2 \alpha}$ at $\mathrm{d}$ 7, $10 \mu \mathrm{g}$ of $\mathrm{GnRH} 60 \mathrm{~h}$ after $\mathrm{PGF}_{2 \alpha}$; animals received TAI $18 \mathrm{~h}$ after the final GnRH injection.

a significant parity effect for the variables listed was reflected by better performance in lower-parity animals compared with older animals. The proportion of Jersey was associated $(P=0.03)$ with 5 -d submission rate relative to each $\mathrm{PB}$ (regression coefficient of the logit of the probability of 5 -d submission relative to each $\mathrm{PB}$ of 0.0324; $\mathrm{SE}=0.0153)$, whereas the proportion Holstein-Friesian was associated $(P=0.02)$ with 21 -d submission relative to each PB (regression coefficient of the logit of the probability of 21-d submission relative to each $\mathrm{PB}$ of $-0.0270 ; \mathrm{SE}=0.0114)$. Also, the proportion Holstein-Friesian was associated $(P=0.02)$ with conception rate at first service (regression coefficient of the logit of the probability of conception of -0.0176 ; $\mathrm{SE}=0.0076)$. The coefficient of recombination loss and proportion Jersey was associated $(P=0.04$ and $P=0.01$, respectively) with 42 -d pregnancy rate (regression coefficient of the logit of the probability of 42-d pregnancy of 1.0322; $\mathrm{SE}=0.5161$ and 0.0302; $\mathrm{SE}=0.0119)$, respectively, whereas the coefficient of heterosis and Jersey proportion were associated $(P=$ 0.04 and $P=0.01$, respectively) with the interval from
MSDC (regression coefficient of $0.22067 ; \mathrm{SE}=0.10921$ and 0.01295; $\mathrm{SE}=0.00522$ ), respectively.

The effect of synchronization treatment on 5- and 21-d submission rate relative to each $\mathrm{PB}$ for CIDR OBS and CTRL groups is summarized in Table 1. The intercept of the multiple regression model for 5 - and 21-d submission rate relative to each $\mathrm{PB}$ was -0.65 (SE $=0.3)$ and $2.33(\mathrm{SE}=0.4)$, respectively. Both TAI protocols resulted in 5- and 21-d submission rates relative to each PB of 1.00. Synchronization treatment $(P<$ $0.001)$, calving group $(P=0.009)$, and their interaction $(P=0.056)$ had significant effects on 5 -d submission rate relative to each $\mathrm{PB}$. The CIDR_OBS group had increased odds of being submitted for insemination in the first 5 d relative to each PB compared with the CTRL $(P<0.001)$. The significant interaction observed was due to the lower 5 -d submission rate for CTRL animals in the mid-calving group relative to CTRL animals in the early and late-calving groups, whereas the 5 -d submission rate was similar for all calving groups on the CIDR_OBS treatment. The 5-d submission rate relative to each PB for CTRL animals in the mid- and 
late-calving groups represents the proportion of CTRL animals inseminated during the 5-d period following PB2 and PB3. However, CTRL animals in the midand late-calving groups were eligible for AI from the time CIDR_OBS, CIDR_TAI, and Ovsynch were assigned to synchronization treatments on d 11 and 32 , respectively. If the CTRL animals inseminated in the 10-d period that synchronization treatments were imposed were reported, an additional 23 (mid) and 9 (late) CTRL cows would have been included, increasing the 5-d submission rate for CTRL cows in the mid- and late-calving groups to 0.63 and 0.75 , respectively.

Synchronization treatment $(P=0.04)$, calving group $(P<0.001)$, and their interaction $(P<0.001)$ had significant effects on 21-d submission rate relative to each PB. The CIDR_OBS group had increased odds of being submitted for insemination in the first $21 \mathrm{~d}$ relative to each $\mathrm{PB}$ compared with the CTRL $(P=$ $0.04)$. The observed significant interaction was due to the lower 21-d submission rate for CTRL animals in the mid- and late-calving groups compared with the early calving group, whereas the 21 -d submission rate was similar for all calving groups on the CIDR_OBS treatment. The 21-d submission rate relative to each PB for CTRL animals in the mid- and late-calving groups represents the proportion of CTRL animals inseminated during the 21-d period following PB2 and PB3. However, CTRL animals in the mid- and late-calving groups were eligible for AI from the time CIDR_OBS, CIDR_TAI, and Ovsynch were assigned to synchronization treatments on d 11 and 32, respectively. If the CTRL animals inseminated in the 10-d period that synchronization treatments were imposed were reported, the inclusion of an additional 23 (mid) and 9 (late) CTRL cows would have increased the 21-d submission rate for CTRL cows in the mid- and latecalving groups to 0.77 and 0.97 , respectively.

The effect of synchronization treatment on overall 21-d submission rate is summarized in Table 1. The intercept of the multiple regression model for overall

Table 1. Effect of synchronization treatment and calving group on 5-d submission rate (SR) relative to each planned breeding (PB), 21-d SR relative to each PB, and overall 21-d SR relative to mating start date (MSD) ${ }^{1}$

\begin{tabular}{|c|c|c|c|c|c|}
\hline \multirow{2}{*}{$\begin{array}{l}\text { Synchronization } \\
\text { treatment }^{2}\end{array}$} & \multirow{2}{*}{$\begin{array}{l}\text { Odds ratio } \\
(95 \% \mathrm{CI})\end{array}$} & \multicolumn{4}{|c|}{ Predicted probability $^{3}(\mathrm{SE})$} \\
\hline & & All cows & Early & Mid & Late \\
\hline \multicolumn{6}{|c|}{ 5-d SR for each $\mathrm{PB}^{4}$} \\
\hline CIDR_OBS & $\begin{array}{l}8.73 \\
(6.22,12.25)\end{array}$ & $0.81(0.02)^{\mathrm{a}}$ & $0.83(0.02)^{\mathrm{a}}$ & $0.77(0.06)^{\mathrm{a}}$ & $0.74(0.08)^{\mathrm{a}}$ \\
\hline CTRL & 1.00 & $0.33(0.02)^{\mathrm{b}}$ & $0.37(0.03)^{\mathrm{b}, \mathrm{x}}$ & $0.11(0.05)^{\mathrm{b}, \mathrm{y}}$ & $0.41(0.09)^{\mathrm{b}, \mathrm{x}}$ \\
\hline \multicolumn{6}{|c|}{ 21-d SR for each $\mathrm{PB}^{4}$} \\
\hline CIDR_OBS & $\begin{array}{l}1.55 \\
(1.02,2.34)\end{array}$ & $0.89(0.02)^{\mathrm{a}}$ & $0.90(0.02)$ & $0.89(0.05)^{\mathrm{a}}$ & $0.83(0.06)$ \\
\hline CTRL & 1.00 & $0.84(0.02)^{\mathrm{b}}$ & $0.93(0.01)^{\mathrm{x}}$ & $0.28(0.07)^{\mathrm{b}, \mathrm{y}}$ & $0.67(0.09)^{\mathrm{z}}$ \\
\hline \multicolumn{6}{|l|}{$\begin{array}{l}\text { Overall 21-d SR } \\
\text { relative to MSD }\end{array}$} \\
\hline CIDR_OBS & $\begin{array}{l}0.82 \\
(0.58,1.16)\end{array}$ & $0.78(0.02)^{\mathrm{a}}$ & - & - & - \\
\hline CIDR_TAI & $\begin{array}{l}3.15 \\
(1.98,5.00)\end{array}$ & $0.93(0.01)^{\mathrm{b}}$ & - & - & - \\
\hline Ovsynch & $\begin{array}{l}3.32 \\
(2.06,5.34)\end{array}$ & $0.94(0.01)^{\mathrm{b}}$ & - & - & - \\
\hline CTRL & 1.00 & $0.82(0.02)^{\mathrm{a}}$ & - & - & - \\
\hline
\end{tabular}

${ }_{\mathrm{a}, \mathrm{b}}$ Predicted probabilities within a column with different superscripts differ $(P<0.05)$.

${ }^{\mathrm{x}-\mathrm{z}}$ Predicted probabilities within a row with different superscripts differ $(P<0.05)$.

${ }^{1}$ Interaction between synchronization treatment and calving group: 5 -d SR for each PB $(P=0.055)$; 21-d SR for each PB $(P<0.001)$.

${ }^{2} \mathrm{CIDR}=$ controlled internal drug release; $\mathrm{OBS}=$ observed estrus; $\mathrm{CTRL}=$ control; TAI $=$ timed AI. CIDR_ OBS $=10 \mu \mathrm{g}$ of GnRH and CIDR insert at d $0,25 \mathrm{mg}$ of $\mathrm{PGF}_{2 \alpha}$ at $\mathrm{d} 7$, CIDR removed at $\mathrm{d} 8$; animals were inseminated by the a.m./p.m. rule, following detection of estrus on d 10, 11, and 12. CIDR_TAI $=10 \mu \mathrm{g}$ of GnRH and CIDR insert at $\mathrm{d}$ 0, $25 \mathrm{mg}$ of $\mathrm{PGF}_{2 \alpha}$ at $\mathrm{d}$ 7, CIDR removed at $\mathrm{d} 8,10 \mu \mathrm{g}$ of $\mathrm{GnRH} 60 \mathrm{~h}$ after $\mathrm{PGF}_{2 \alpha}$ or $36 \mathrm{~h}$ after CIDR removal; animals received TAI $18 \mathrm{~h}$ after the final GnRH injection. Ovsynch $=10 \mu \mathrm{g}$ of $\mathrm{GnRH}$ at d $0,25 \mathrm{mg}$ of $\mathrm{PGF}_{2 \alpha}$ at d 7, $10 \mu \mathrm{g}$ of $\mathrm{GnRH} 60 \mathrm{~h}$ after $\mathrm{PGF}_{2 \alpha}$; animals received TAI $18 \mathrm{~h}$ after the final GnRH injection.

${ }^{3}$ Predicted probabilities are based on a cow from the average farm and are representative of the parity and calving date structure in the data. Early, mid, and late refer to time of calving and are based on DIM at the farm MSD.

${ }^{4}$ For CIDR_TAI and Ovsynch, 5-d and 21-d submission rate relative to each PB was 1.00, and hence, these animals were removed from the analysis of 5 - $\mathrm{d}$ and 21 - $\mathrm{d}$ submission rate relative to each $\mathrm{PB}$. 
21 -d submission rate was $1.50(\mathrm{SE}=0.29)$. Due to a confounding effect between calving group and overall 21-d submission rate, calving group was removed from the statistical model for this variable. Synchronization treatment had a significant effect on overall 21-d submission rate $(P<0.001)$. Both CIDR_TAI and Ovsynch animals had increased odds of being submitted for insemination in the first $21 \mathrm{~d}$ of the breeding season compared with the CTRL (both $P<0.001$ ). The CIDR_OBS animals had decreased likelihood of being submitted for insemination in the first $21 \mathrm{~d}$ of the breeding season compared with CIDR_TAI and Ovsynch animals $(\mathrm{OR}=0.26, P<0.001 ;$ and $\mathrm{OR}=$ $0.25, P<0.001$, respectively).

The effect of synchronization treatment on conception rate at first service is summarized in Table 2. The intercept of the multiple regression model for conception rate at first service was $0.15(\mathrm{SE}=0.2)$. Synchronization treatment had a significant effect on conception rate at first service $(P=0.0009)$, but calving group and the interaction between synchronization treatment and calving group were not significant $(P=0.8$ and $P$ $=0.3$, respectively). Both CIDR_OBS and CIDR_TAI animals had increased odds of conceiving at first service compared with Ovsynch $(\mathrm{OR}=1.81, P<0.001$; and $\mathrm{OR}=1.46, P=0.01$, respectively), and Ovsynch animals had decreased likelihood of conceiving at first service compared with the CTRL $(\mathrm{OR}=0.70, P=$ 0.02). Animals inseminated based on observed estrus had an increased likelihood of conceiving at first service compared with animals bred with TAI $(\mathrm{OR}=1.33, P=$ $0.007)$. No effect was observed of synchronization treatment $(P=0.8)$, calving group $(P=0.8)$, or their inter- action $(P=0.3)$ on conception rate at second service, and none of the synchronization treatments had OR that differed from the CTRL treatment. The intercept of the multiple regression model for conception rate at second service was $0.18(\mathrm{SE}=0.3)$. The mean conception rate at second AI across all treatments was 0.56.

The effect of synchronization treatment on embryo loss after first service is summarized in Table 3 . The intercept of the multiple regression model for embryo loss after first service was $-3.36(\mathrm{SE}=0.6)$. Synchronization treatment had a significant effect on embryo loss after first service $(P=0.05)$, but calving group and the interaction between synchronization treatment and calving group were not significant $(P=0.6$ and $P=0.9$, respectively). The Ovsynch animals had increased odds of embryo loss after first service $(P=0.0097)$ compared with the CTRL. Both CIDR_OBS and CIDR_TAI animals tended to have increased odds of embryo loss after first service compared with the CTRL $(P=0.10$ and $P=0.07$, respectively). Control animals had decreased likelihood of embryo loss after first service compared with animals bred with either TAI protocols $(\mathrm{OR}=$ $0.35, P=0.02)$ or CIDR-based protocols $(\mathrm{OR}=0.44, P$ $=0.06)$. Animals that conceived following insemination at observed estrus had decreased likelihood of embryo loss after first service compared with animals bred with TAI (predicted probability of embryo loss after first service $=0.05$ vs. $0.09 ; \mathrm{OR}=0.52, P=0.03$ ).

The effect of synchronization treatment on 42-d pregnancy rate is summarized in Table 4 . The intercept of the multiple regression model for 42 -d pregnancy rate was 1.01 ( $\mathrm{SE}=0.2$ ). No overall effect of synchronization treatment on $42-\mathrm{d}$ pregnancy rate was observed $(P$

Table 2. Effect of synchronization treatment and calving group on conception rate at first service ${ }^{1}$

\begin{tabular}{|c|c|c|c|c|c|}
\hline \multirow{2}{*}{$\begin{array}{l}\text { Synchronization } \\
\text { treatment }^{2}\end{array}$} & \multirow{2}{*}{$\begin{array}{l}\text { Odds ratio } \\
(95 \% \text { CI })\end{array}$} & \multicolumn{4}{|c|}{ Predicted probability $^{3}$ (SE) } \\
\hline & & All cows & Early & Mid & Late \\
\hline CIDR_OBS & $\begin{array}{l}1.28 \\
(0.96,1.70)\end{array}$ & $0.59(0.02)^{\mathrm{a}}$ & $0.58(0.03)$ & $0.72(0.07)$ & $0.53(0.09)$ \\
\hline CIDR_TAI & $\begin{array}{l}1.03 \\
(0.77,1.37)\end{array}$ & $0.54(0.03)^{\mathrm{a}}$ & $0.54(0.03)$ & $0.51(0.08)$ & $0.58(0.09)$ \\
\hline Ovsynch & $\begin{array}{l}0.70 \\
(0.53,0.94)\end{array}$ & $0.45(0.03)^{\mathrm{b}}$ & $0.47(0.03)$ & $0.35(0.07)$ & $0.33(0.09)$ \\
\hline CTRL & 1.00 & $0.53(0.03)^{\mathrm{a}}$ & $0.55(0.03)$ & $0.47(0.07)$ & $0.54(0.10)$ \\
\hline
\end{tabular}

a,b Predicted probabilities within a column with different superscripts differ $(P<0.05)$.

${ }^{1}$ Interaction between synchronization treatment and calving group $(P=0.2)$.

${ }^{2} \mathrm{CIDR}=$ controlled internal drug release; OBS = observed estrus; $\mathrm{TAI}=$ timed $\mathrm{AI}$; CTRL $=$ control. CIDR OBS $=10 \mu \mathrm{g}$ of $\mathrm{GnRH}$ and CIDR insert at $\mathrm{d} 0,25 \mathrm{mg}$ of $\mathrm{PGF}_{2 \alpha}$ at d 7, CIDR removed at $\mathrm{d} 8$; animals were inseminated by the a.m./p.m. rule, following detection of estrus on d 10,11, and 12. CIDR_TAI $=10 \mu \mathrm{g}$ of GnRH and CIDR insert at d 0,25 $\mathrm{mg}$ of $\mathrm{PGF}_{2 \alpha}$ at d 7, CIDR removed at d 8, $10 \mu \mathrm{g}$ of GnRH $60 \mathrm{~h}$ after $\mathrm{PGF}_{2 \alpha}$ or $36 \mathrm{~h}$ after CIDR removal; animals received TAI $18 \mathrm{~h}$ after the final GnRH injection. Ovsynch $=10 \mu \mathrm{g}$ of GnRH at d 0, $25 \mathrm{mg}$ of $\mathrm{PGF}_{2 \alpha}$ at d 7, $10 \mu \mathrm{g}$ of $\mathrm{GnRH} 60 \mathrm{~h}$ after $\mathrm{PGF}_{2 \alpha}$; animals received TAI $18 \mathrm{~h}$ after the final GnRH injection.

${ }^{3}$ Predicted probabilities are based on a cow from the average farm and are representative of the parity and calving date structure in the data. Early, mid, and late refer to time of calving and are based on DIM at the farm mating start date. 
$=0.11)$; however, the CIDR_TAI treatment resulted in greater 42-d pregnancy rate compared with the CTRL. None of the other treatments differed from each other. Calving group had a significant effect on 42 -d pregnancy rate $(P<0.001)$, and the interaction between synchronization treatment and calving group tended toward significance $(P=0.08)$. This was due to the tendency for greater 42-d pregnancy rates in the synchronized animals in the mid and late groups compared with the CTRL.

Synchronization treatment and calving group had a significant effect on CSI (both $P<0.001$ ), but the interaction between synchronization treatment and calving group was not significant $(P=0.3)$. The intercept of the fixed effects linear model for CSI was $77.88 \mathrm{~d}$ (SE $=1.4 \mathrm{~d})$. Least squares means $( \pm \mathrm{SE})$ for CSI were 69.2 $\mathrm{d}(0.7), 63.4 \mathrm{~d}(0.7), 63.7 \mathrm{~d}(0.7)$, and $73.7 \mathrm{~d}(0.7)$ for CIDR_OBS, CIDR_TAI, Ovsynch, and CTRL, respectively. All synchronization treatments had shorter $(P<$ 0.001) intervals from calving to first service compared with the CTRL. The CIDR_TAI and OSYNCH animals had shorter CSI compared with CIDR_OBS animals $(P$ $<0.001$ ), and CIDR_TAI and Ovsynch animals did not differ $(P=0.8)$.

Synchronization treatment $(P=0.03)$ and calving group $(P<0.001)$ affected the interval from MSDC, but the interaction term was not significant $(P=0.8)$. Both CIDR_TAI $[\mathrm{HR}(95 \% \mathrm{CI})=1.21(1.04,1.41), P$ $=0.02]$ and Ovsynch $[\mathrm{HR}(95 \% \mathrm{CI})=1.23(1.05,1.44)$, $P=0.0089]$ animals were associated with an increased likelihood of earlier conception compared with the
CTRL (Figure 3). A tendency for increased likelihood of earlier conception was observed for CIDR_OBS animals compared with the CTRL $[\mathrm{HR}(95 \% \mathrm{CI})=1.15$ (0.99, 1.34), $P=0.06]$. Control animals had decreased likelihood of earlier conception compared with animals bred with TAI $(\mathrm{HR}=0.82, P=0.003)$. Animals inseminated based on observed estrus had a decreased likelihood of earlier conception compared with animals bred with TAI $(\mathrm{HR}=0.88, P=0.02)$. Control animals had decreased likelihood of earlier conception compared with animals assigned to the CIDR-based protocols $(\mathrm{HR}=0.85, P=0.01)$. The median MSDC for CIDR_OBS, CIDR_TAI, Ovsynch, and CTRL animals was $33.2,30.9,32.1$, and $37.1 \mathrm{~d}$, respectively.

The effect of synchronization treatment on synchronization rate is summarized in Table 5 . The intercept of the multiple regression model was $2.03(\mathrm{SE}=0.4)$. Synchronization treatment had a significant effect on synchronization rate $(P<0.001)$, but calving group and the interaction between synchronization treatment and calving group were not significant $(P=0.19$ and $P=0.13$, respectively). The proportion of animals on synchronization treatments in the $\mathrm{P} 4$ categories were as follows: $\mathrm{LH}(\mathrm{n}=1,012 ; 89.4 \%)$, $\mathrm{LL}(\mathrm{n}=100 ; 8.83 \%)$, HL $(\mathrm{n}=8 ; 0.71 \%)$, and HH $(\mathrm{n}=12 ; 1.06 \%)$. The CIDR_TAI animals had increased likelihood of being synchronized compared with CIDR_OBS $(\mathrm{OR}=3.79$, $P<0.001)$ and Ovsynch $(\mathrm{OR}=4.50, P<0.001)$, but no difference existed between CIDR_OBS and Ovsynch $(P=0.4)$. The proportion of CTRL animals in the P4 categories were as follows: LH $(\mathrm{n}=115 ; 30.8 \%)$, LL

Table 3. Effect of synchronization treatment and calving group on embryo loss after first service ${ }^{1}$

\begin{tabular}{|c|c|c|c|c|c|}
\hline \multirow{2}{*}{$\begin{array}{l}\text { Synchronization } \\
\text { treatment }^{2}\end{array}$} & \multirow{2}{*}{$\begin{array}{l}\text { Odds ratio } \\
(95 \% \text { CI })\end{array}$} & \multicolumn{4}{|c|}{ Predicted probability $^{3}(\mathrm{SE})$} \\
\hline & & All cows & Early & Mid & Late \\
\hline CIDR_OBS & $\begin{array}{l}2.16 \\
(0.86,5.43)\end{array}$ & $0.06(0.02)^{\mathrm{ab}}$ & $0.06(0.02)$ & $0.10(0.05)$ & $0.05(0.05)$ \\
\hline CIDR_TAI & $\begin{array}{l}2.38 \\
(0.94,6.01)\end{array}$ & $0.07(0.02)^{\mathrm{ab}}$ & $0.08(0.02)$ & $0^{4}$ & $0.06(0.06)$ \\
\hline Ovsynch & $\begin{array}{l}3.35 \\
(1.34,8.35)\end{array}$ & $0.10(0.02)^{\mathrm{a}}$ & $0.12(0.03)$ & $0^{4}$ & $0^{4}$ \\
\hline CTRL & 1.00 & $0.03(0.01)^{\mathrm{b}}$ & $0.03(0.01)$ & $0.05(0.05)$ & $0.06(0.06)$ \\
\hline \multicolumn{6}{|c|}{$\overline{\mathrm{a}, \mathrm{b}}$ Predicted probabilities within a column with different superscripts differ $(P<0.05)$. } \\
\hline \multicolumn{6}{|c|}{ 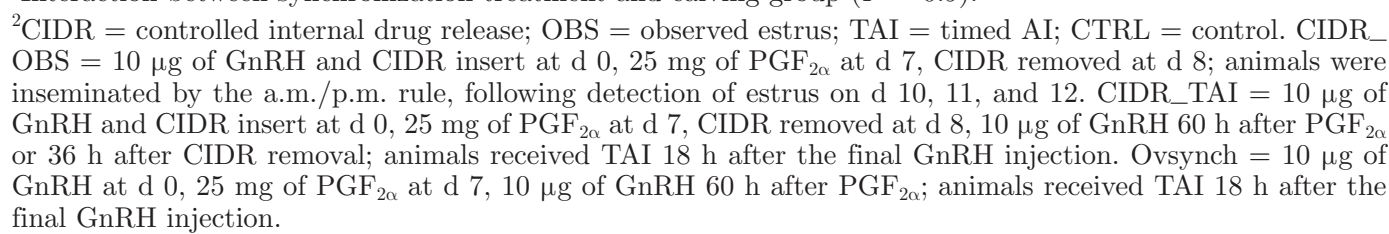 } \\
\hline \multicolumn{6}{|c|}{$\begin{array}{l}{ }^{3} \text { Predicted probabilities are based on a cow from the average farm and are representative of the parity and } \\
\text { calving date structure in the data. Early, mid, and late refer to time of calving and are based on DIM at the } \\
\text { farm mating start date. }\end{array}$} \\
\hline${ }^{4}$ None of the anin & this synchron & ion treatment & in this groul & perienced emb & loss after first \\
\hline
\end{tabular}


Table 4. Effect of synchronization treatment and calving group on 42-d pregnancy rate ${ }^{1}$

\begin{tabular}{|c|c|c|c|c|c|}
\hline \multirow{2}{*}{$\begin{array}{l}\text { Synchronization } \\
\text { treatment }^{2}\end{array}$} & \multirow{2}{*}{$\begin{array}{l}\text { Odds ratio } \\
(95 \% \text { CI })\end{array}$} & \multicolumn{4}{|c|}{ Predicted probability $^{3}(\mathrm{SE})$} \\
\hline & & All cows & Early & Mid & Late \\
\hline CIDR_OBS & $\begin{array}{l}1.23 \\
(0.89,1.70)\end{array}$ & $0.71(0.02)^{b c}$ & $0.76(0.02)^{\mathrm{x}}$ & $0.69(0.07)^{a, x}$ & $0.32(0.08)^{\mathrm{a}, \mathrm{y}}$ \\
\hline CIDR_TAI & $\begin{array}{l}1.52 \\
(1.09,2.12)\end{array}$ & $0.75(0.02)^{\mathrm{ac}}$ & $0.78(0.02)^{\mathrm{x}}$ & $0.64(0.07)^{\mathrm{ab}, \mathrm{y}}$ & $0.58(0.09)^{\mathrm{b}, y}$ \\
\hline Ovsynch & $\begin{array}{l}1.25 \\
(0.90,1.74)\end{array}$ & $0.71(0.02)^{\mathrm{bc}}$ & $0.79(0.02)^{\mathrm{x}}$ & $0.48(0.07)^{\mathrm{bc}, y}$ & $0.33(0.09)^{\mathrm{ab}, \mathrm{y}}$ \\
\hline CTRL & 1.00 & $0.67(0.02)^{\mathrm{b}}$ & $0.75(0.02)^{\mathrm{x}}$ & $0.42(0.07)^{\mathrm{c}, \mathrm{y}}$ & $0.27(0.09)^{\mathrm{a}, \mathrm{y}}$ \\
\hline
\end{tabular}

${ }^{\mathrm{a}-\mathrm{c}}$ Predicted probabilities within a column with different superscripts differ $(P<0.05)$.

${ }^{\mathrm{x}, \mathrm{y}}$ Predicted probabilities within a row with different superscripts differ $(P<0.05)$.

${ }^{1}$ Interaction between synchronization treatment and calving group $(P=0.08)$.

${ }^{2} \mathrm{CIDR}=$ controlled internal drug release; OBS $=$ observed estrus; TAI $=$ timed AI; CTRL $=$ control. CIDR $\mathrm{OBS}=10 \mu \mathrm{g}$ of $\mathrm{GnRH}$ and CIDR insert at d $0,25 \mathrm{mg}$ of $\mathrm{PGF}_{2 \alpha}$ at $\mathrm{d} 7$, CIDR removed at $\mathrm{d} 8$; animals were inseminated by the a.m./p.m. rule, following detection of estrus on d 10,11, and 12. CIDR_TAI $=10 \mu \mathrm{g}$ of GnRH and CIDR insert at d 0, $25 \mathrm{mg}$ of $\mathrm{PGF}_{2 \alpha}$ at d 7, CIDR removed at d 8, $10 \mu \mathrm{g}$ of GnRH $60 \mathrm{~h}$ after $\mathrm{PGF}_{2 \alpha}$ or $36 \mathrm{~h}$ after CIDR removal; animals received TAI $18 \mathrm{~h}$ after the final GnRH injection. Ovsynch $=10 \mu \mathrm{g}$ of $\mathrm{GnRH}$ at $\mathrm{d} 0,25 \mathrm{mg}$ of $\mathrm{PGF}_{2 \alpha}$ at $\mathrm{d} 7,10 \mu \mathrm{g}$ of $\mathrm{GnRH} 60 \mathrm{~h}$ after $\mathrm{PGF}_{2 \alpha}$; animals received TAI $18 \mathrm{~h}$ after the final GnRH injection.

${ }^{3}$ Predicted probabilities are based on a cow from the average farm and are representative of the parity and calving date structure in the data. Early, mid, and late refer to time of calving and are based on DIM at the farm mating start date.

$(\mathrm{n}=54 ; 14.4 \%), \mathrm{HL}(\mathrm{n}=65 ; 17.4 \%)$, and $\mathrm{HH}(\mathrm{n}=$ $140 ; 37.4 \%)$. Therefore, $85.6 \%$ of the CTRL cows were considered to be cycling normally during the period of synchronization treatments.

\section{DISCUSSION}

The present study compared the reproductive performance of seasonal-calving lactating dairy cows following treatment with protocols to synchronize estrus or ovulation with that of non-synchronized cows. This study provided a valuable opportunity to investigate the potential of aggressive synchronization as a tool to alter the calving pattern of dairy cows in seasonal calving systems. Experimental treatments were imposed on all cows that had calved up to and including the MSD, thus maximizing the proportion of the herd bred with AI during the first $42 \mathrm{~d}$ of the breeding season, a parameter of particular importance in seasonal calving herds. Use of TAI protocols resulted in shorter intervals from calving to first service and from mating start date to conception. Progesterone supplementation as part of a TAI protocol resulted in a higher proportion of these animals successfully establishing pregnancy during the first $42 \mathrm{~d}$ of the breeding season.

Achieving high submission rates within the first $21 \mathrm{~d}$ of the breeding season is a prerequisite for a compact calving pattern the following spring (Diskin and Sreenan, 2000). The overall 21-d submission rate for animals in the present study was in line with targets set down for seasonal calving systems (McDougall, 2006), and similar to submission rates recently achieved on Irish dairy farms (Buckley et al., 2003). The 21-d submission rate for CTRL cows in the early calving group, which represented CTRL animals calved the longest period of time, was in line with targets for seasonal calving systems (McDougall, 2006). However, CTRL animals in the mid- and late-calving groups had lower submission rates, presumably reflecting closer proximity to calving in these groups compared with the early calving group. These results highlight the considerable challenge associated with later-calving cows in seasonal-calving systems (Grosshans et al., 1997). The 5-d submission rate relative to each PB for CIDR_OBS averaged 0.81, and indicated that an acceptable proportion of animals displayed estrus and were submitted for insemination within the first $5 \mathrm{~d}$ relative to each $\mathrm{PB}$. In the present study, the CIDR device was inserted for $8 \mathrm{~d}$ and removed $1 \mathrm{~d}$ after the $\mathrm{PGF}_{2 \alpha}$ injection based on previous reports of improved precision in the onset of estrus when CIDR inserts were removed after an 8-d treatment period (Xu and Burton, 2000). Using a similar protocol, Ryan et al. (1995) and Ryan et al. (1999) reported that 88.5 and $87.5 \%$ of animals, respectively, were detected in estrus and submitted for insemination by $\mathrm{d} 4$ after the start of the breeding period.

The challenge of low submission rates can be overcome by incorporating TAI protocols into reproductive management programs (Lucy et al., 2004). Ovsynch has been successfully used for synchronizing follicular wave development, luteolysis, and ovulation in lactating dairy cows (Pursley et al., 1995, 1997). The use of TAI protocols in the current study ensured that all animals assigned to TAI protocols in the early, mid-, and 
Table 5. Effect of synchronization treatment and calving group on synchronization rate ${ }^{1}$

\begin{tabular}{|c|c|c|c|c|c|}
\hline \multirow{2}{*}{$\begin{array}{l}\text { Synchronization } \\
\text { treatment }^{2}\end{array}$} & \multirow{2}{*}{$\begin{array}{l}\text { Odds ratio } \\
(95 \% \mathrm{CI})\end{array}$} & \multicolumn{4}{|c|}{ Predicted probability $^{3}$ (SE) } \\
\hline & & All cows & Early & Mid & Late \\
\hline CIDR_OBS & $\begin{array}{l}1.19 \\
(0.78,1.82)\end{array}$ & $0.90(0.02)^{\mathrm{a}}$ & $0.91(0.02)$ & $0.87(0.05)$ & $0.84(0.06)$ \\
\hline CIDR_TAI & $\begin{array}{l}4.50 \\
(2.47,8.20)\end{array}$ & $0.97(0.01)^{\mathrm{b}}$ & $0.97(0.01)$ & $0.97(0.03)$ & $1.00(0)$ \\
\hline Ovsynch & 1.00 & $0.88(0.02)^{\mathrm{a}}$ & $0.89(0.02)$ & $0.93(0.04)$ & $0.72(0.09)$ \\
\hline
\end{tabular}

${ }_{\mathrm{a}, \mathrm{b}}$ Predicted probabilities within a column with different superscripts differ $(P<0.05)$.

${ }^{1}$ Interaction between synchronization treatment and calving group $(P=0.13)$.

${ }^{2} \mathrm{CIDR}=$ controlled internal drug release OBS $=$ observed estrus; TAI $=$ timed AI. CIDR_OBS $=10 \mu \mathrm{g}$ of GnRH and CIDR insert at d 0,25 $\mathrm{mg}$ of $\mathrm{PGF}_{2 \alpha}$ at $\mathrm{d} 7$, CIDR removed at $\mathrm{d}$ 8; animals were inseminated by the a.m./p.m. rule, following detection of estrus on $\mathrm{d} 10,11$, and 12 . CIDR_TAI $=10 \mu \mathrm{g}$ of GnRH and CIDR insert at $\mathrm{d} 0,25 \mathrm{mg}$ of $\mathrm{PGF}_{2 \alpha}$ at $\mathrm{d}$ 7, CIDR removed at $\mathrm{d} 8,10 \mu \mathrm{g}$ of $\mathrm{GnRH} 60 \mathrm{~h}$ after $\mathrm{PGF}_{2 \alpha}$ or $36 \mathrm{~h}$ after CIDR removal; animals received TAI $18 \mathrm{~h}$ after the final $\mathrm{GnRH}$ injection. Ovsynch $=10 \mu \mathrm{g}$ of $\mathrm{GnRH}$ at d $0,25 \mathrm{mg}$ of $\mathrm{PGF}_{2 \alpha}$ at $\mathrm{d}$ 7, $10 \mu \mathrm{g}$ of $\mathrm{GnRH} 60 \mathrm{~h}$ after $\mathrm{PGF}_{2 \alpha}$; animals received TAI $18 \mathrm{~h}$ after the final $\mathrm{GnRH}$ injection. ${ }^{3}$ Predicted probabilities are based on a cow from the average farm and are representative of the parity and calving date structure in the data. Early, mid, and late refer to time of calving and are based on DIM at the farm mating start date.

late-calving groups were submitted for insemination on PB1, PB2, and PB3, respectively. Although a significant improvement in submission rate was achieved with the use of CIDR_OBS compared with the CTRL, the values for $5 \mathrm{~d}(0.81$ vs. 0.33$)$ and $21 \mathrm{~d}(0.89 \mathrm{vs}$. $0.84)$ submission rates relative to each $\mathrm{PB}$ were considerably lower than the pre-determined value of 1 for animals assigned to TAI protocols. The positive effect of TAI protocols on submission rate was particularly apparent when evaluating the 5-d submission rate for CIDR_OBS in the mid- (0.77) and late- (0.74) calving groups. The use of TAI protocols resulted in more cows submitted for insemination earlier in the breeding season compared with CIDR_OBS and CTRL treatments. An increase in submission rates with TAI protocols was observed for all calving groups, but the effect was greatest in the later-calving cows. A major limitation of the CIDR_OBS protocol was that the submission rate achieved was dependent on estrous behavior and estrus detection efficiency.

The conception rate to first service of cows assigned to Ovsynch was lower when compared with all other treatments. In agreement with previous studies, P4 supplementation during the treatment protocol was associated with more favorable pregnancy outcomes compared with Ovsynch, whether animals receiving supplemental P4 were inseminated based on observed estrus or TAI (Melendez et al., 2006; Chebel et al., 2010; McDougall, 2010;). The highest conception rate at first service was obtained with the CIDR_OBS protocol. Conception rate at first service for CIDR_OBS animals in the current study was similar to that in the first of 2 trials reported by Xu and Burton (2000; 56.5\%), where animals were treated with $\mathrm{GnRH}$ and an intravaginal $\mathrm{P} 4$ device, followed $7 \mathrm{~d}$ later by $\mathrm{PGF}_{2 \alpha}$, and removal of the $\mathrm{P} 4$ device $1 \mathrm{~d}$ after $\mathrm{PGF}_{2 \alpha}$. However, in the second trial, $\mathrm{Xu}$ and Burton (2000) reported an improvement in conception rates $(64.6 \%)$ when the duration of $\mathrm{P} 4$ treatment was decreased from 8 to $7 \mathrm{~d}$ and CIDR removal occurred concurrent with $\mathrm{PGF}_{2 \alpha}$ injection. Xu and Burton (2000) concluded that the extra day of P4 treatment after $\mathrm{PGF}_{2 \alpha}$ injection in the first trial may have allowed some dominant follicles to be maintained for a longer period, resulting in the ovulation of aged oocytes with decreased developmental competence. Using a comparable protocol to CIDR_OBS (Ryan et al., 1995) reported similar pregnancy rates (57.9\%); however, a protocol that did not include $\mathrm{GnRH}$ at the time of CIDR insertion was associated with an 11- to 14-percentage unit decrease in pregnancy rates (46.6\%).

Addition of $\mathrm{P} 4$ to Ovsynch (CIDR_TAI) resulted in 0.09 greater first-service conception rate when compared with Ovsynch. In agreement with the results from the current study and the majority of studies not using presynchronization, the first of 2 experiments completed by El-Zarkouny et al. (2004) reported higher pregnancy rates at $29 \mathrm{~d}$ post-AI (59.3 vs. $36.3 \%$ ) for animals supplemented with $\mathrm{P} 4$ during Ovsynch compared with animals treated with the standard Ovsynch protocol. However, in a second experiment, when presynchronization was used, El-Zarkouny et al. (2004) reported that P4 supplementation appeared to offer no improvement in pregnancies per AI over Ovsynch alone. McDougall (2010) reported that addition of P4 to Ovsynch for anestrous cows tended to increase 21-d pregnancy rate compared with anestrous cows treated with Ovsynch (57.5 vs. $48.4 \%$ ). In the same study, addition of $\mathrm{P} 4$ to Ovsynch resulted in more cows with normal subsequent luteal-phase lengths. An 8.5-percentage unit improvement in pregnancy rate was reported by 
Melendez et al. (2006) for animals not previously detected in estrus following presynchronization, that were supplemented with $\mathrm{P} 4$ during Ovsynch compared with animals treated with Ovsynch alone (31.2 vs. 22.7\%). Following a $\mathrm{PGF}_{2 \alpha}$-based presynchronization protocol, Stevenson et al. (2008) compared pregnancies per AI in cows without a corpus luteum at the first $\mathrm{GnRH}$ injection of Ovsynch, receiving or not receiving 7-d P4 supplementation via a CIDR insert with that of cows with a corpus luteum present. It was reported that treatment with a CIDR in cows without a corpus luteum increased pregnancies per $\mathrm{AI}$ at both 33 and 61 $\mathrm{d}$ after TAI, but did not differ from that of cows that had a corpus luteum present at the time of the first GnRH injection of Ovsynch.

In the current study, across ovular and anovular cows at protocol initiation, conception rate to first service using the Ovsynch TAI protocol was similar to that reported by Cordoba and Fricke (2001) for ovular cows managed in grazing-based dairies in Wisconsin. In other studies, conception rates have ranged between 31.3 to $45.0 \%$ following the Ovsynch protocol initiated at random stages of the estrous cycle (Pursley et al., 1997, 1998; Peters and Pursley, 2002, 2003; McDougall, 2010). Lower conception rates following Ovsynch have been reported for anovular cows, possibly due to a higher incidence of premature luteal regression (Gümen et al., 2003). Vasconcelos et al. (1999) reported that initiation of Ovsynch on different days of the estrous cycle affected pregnancy outcome arising from variation in ovulatory responses to the first and second GnRH injection and maximal size of the pre-ovulatory follicle. In the present study, synchronization protocols were initiated at random stages of the estrous cycle with no presynchronization before initiation of synchronization protocols.

The embryo loss rate after first service in the current study was generally low; values were similar for all treatments with the exception of Ovsynch, which had 0.07 greater embryo loss compared with the CTRL. The embryo loss rate for CTRL animals in the current study was lower than the embryonic loss rate of $7.2 \%$ between d 28 and 84 of gestation previously reported in Irish pasture-based herds (Silke et al., 2002) and much lower than embryonic loss rates reported by Gümen et al. (2003) for ovular cows maintained in a high-input TMR system that were inseminated based on observed estrus or TAI (11 vs. 14\%, respectively). The CTRL animals in the present study were inseminated based on observed estrus. For logistical reasons, it was not possible to carry out the pregnancy diagnosis for CTRL cows with the same level of precision as synchronized cows for days post-AI at pregnancy diagnosis. Consequently, both the conception at AI and the embryo loss rate for CTRL animals in the present study may have been slightly underestimated relative to the synchronization treatments. In agreement with McDougall (2010), embryo loss rate did not differ between Ovsynch and CIDR_TAI. In a recent review, Santos et al. (2004) concluded that the majority of studies that implement TAI protocols have reported no difference in embryonic loss rates when TAI has been implemented properly. In the same review, the authors suggested that synchronization protocols that induce estrus with the dominant follicle growing under a low-P4 environment may increase early and late embryo loss, leading to decreased conception rates.

In the present study, only 0.42 and 0.27 of mid- and late-calving CTRL cows successfully established pregnancy during the first $42 \mathrm{~d}$ of the breeding season. Conception rate at first service for CTRL animals was consistent across all calving groups. The decreased submission rates for CTRL cows in the mid- and late-calving groups, therefore, contributed to a significant decrease in the proportion of CTRL cows successfully establishing pregnancy during the first $42 \mathrm{~d}$ of the breeding season. In contrast, a similar conception rate at first service, coupled with a $100 \%$ submission rate for all calving groups, resulted in CIDR_TAI having the highest 42-d pregnancy rate, which is in agreement with the findings of McDougall (2010). A shorter interval from MSD to conception was observed for animals assigned to TAI protocols when compared with the CTRL, similar to the findings of McDougall (2010). In the present study, it is important to note that the submission rate figures for the cows on the CTRL treatment met targets laid down for seasonal-calving systems. Where herds do not routinely meet these targets, the potential effect of aggressive whole-herd synchronization incorporating TAI is increased proportionally to the increase in submission rate achieved.

\section{CONCLUSIONS}

The present study clearly shows that estrus/ovulation can be successfully synchronized with progesterone, $\mathrm{GnRH}$, and $\mathrm{PGF}_{2 \alpha}$ in seasonal-calving dairy cows. Reliance on behavioral estrus/estrus detection limits the submission rates that can be achieved with conventional synchronization protocols. In contrast, TAI protocols ensure that submission rates are maximized, while maintaining acceptable conception rates. Importantly, TAI protocols facilitated earlier first service and earlier conception, increasing the proportion of cows establishing pregnancy during the critical first $42 \mathrm{~d}$ of the breeding season. Supplementation with progesterone during Ovsynch (i.e., CIDR_TAI) increased conception rates. In conclusion, ovulation synchronization protocols are 
an effective tool in the reproductive management of lactating dairy cows in seasonal-calving, pasture-based milk production systems.

\section{ACKNOWLEDGMENTS}

We thank the participating herd owners and their staff for their help and cooperation during the trial. Technical support was provided by Tommy Condon, Billy Curtin, Jonathon Kenneally (all of Teagasc, Animal and Grassland Research and Innovation Centre, Moorepark, Fermoy, Co. Cork, Ireland), Assumpta Glynn (Teagasc, Animal and Grassland Research and Innovation Centre, Athenry, Co. Galway, Ireland), and professional work experience students from University College Dublin (Ireland). Pfizer Ireland (Dublin) donated the CIDR inserts used in this trial. This study was funded by the National Development Plan and the Dairy Levy Trust Fund.

\section{REFERENCES}

Bartolome, J. A., J. J. van Leeuwen, M. Thieme, O. G. Sa'filho, P. Melendez, L. F. Archbald, and W. W. Thatcher. 2009. Synchronization and resynchronization of inseminations in lactating dairy cows with the CIDR insert and the Ovsynch protocol. Theriogenology 72:869-878.

Buckley, F., K. O'Sullivan, J. F. Mee, R. D. Evans, and P. Dillon. 2003. Relationships among milk yield, body condition, cow weight, and reproduction in spring-calved Holstein-Friesians. J. Dairy Sci. $86: 2308-2319$

Chebel, R. C., M. J. Al-Hassan, P. M. Fricke, J. E. Santos, J. R. Lima, C. A. Martel, J. S. Stevenson, R. Garcia, and R. L. Ax. 2010. Supplementation of progesterone via controlled internal drug release inserts during ovulation synchronization protocols in lactating dairy cows. J. Dairy Sci. 93:922-931.

Cordoba, M. C., and P. M. Fricke. 2001. Evaluation of two hormonal protocols for synchronization of ovulation and timed artificial insemination in dairy cows managed in grazing-based dairies. J. Dairy Sci. 84:2700-2708.

Dillon, P., S. Crosse, G. Stakelum, and F. Flynn. 1995. The effect of calving date and stocking rate on the performance of springcalving dairy cows. Grass Forage Sci. 50:286-299.

Diskin, M. G., and J. M. Sreenan. 2000. Expression and detection of oestrus in cattle. Reprod. Nutr. Dev. 40:481-491.

El-Zarkouny, S. Z., J. A. Cartmill, B. A. Hensley, and J. S. Stevenson. 2004. Pregnancy in dairy cows after synchronized ovulation regimens with or without presynchronization and progesterone. J. Dairy Sci. 87:1024-1037.

Grosshans, T., Z. Z. Xu, L. J. Burton, D. L. Johnson, and K. L. Macmillan. 1997. Performance and genetic parameters for fertility of seasonal dairy cows in New Zealand. Livest. Prod. Sci. 51:41-51.

Gümen, A., J. N. Guenther, and M. C. Wiltbank. 2003. Follicular size and response to Ovsynch versus detection of estrus in anovular and ovular lactating dairy cows. J. Dairy Sci. 86:3184-3194.

Horan, B., P. Dillon, P. Faverdin, L. Delaby, F. Buckley, and M. Rath. 2005a. The interaction of strain of Holstein-Friesian cows and pasture-based feed systems on milk yield, body weight, and body condition score. J. Dairy Sci. 88:1231-1243.

Horan, B., J. F. Mee, P. O'Connor, M. Rath, and P. Dillon. 2005b. The effect of strain of Holstein-Friesian cow and feeding system on postpartum ovarian function, animal production and conception rate to first service. Theriogenology 63:950-971.
Lucy, M. C., S. McDougall, and D. P. Nation. 2004. The use of hormonal treatments to improve the reproductive performance of lactating dairy cows in feedlot or pasture-based management systems. Anim. Reprod. Sci. 82-83:495-512.

McCarthy, S., B. Horan, P. Dillon, P. O'Connor, M. Rath, and L. Shalloo. 2007. Economic comparison of divergent strains of Holstein-Friesian cows in various pasture-based production systems. J. Dairy Sci. 90:1493-1505.

McDougall, S. 2006. Reproduction performance and management of dairy cattle. J. Reprod. Dev. 52:185-194.

McDougall, S. 2010. Effects of treatment of anestrous dairy cows with gonadotropin-releasing hormone, prostaglandin, and progesterone. J. Dairy Sci. 93:1944-1959.

Mee, J. F., F. Buckley, D. Ryan, and P. Dillon. 2009. Pre-breeding ovaro-uterine ultrasonography and its relationship with first service pregnancy rate in seasonal-calving dairy herds. Reprod. Domest. Anim. 44:331-337.

Melendez, P., G. Gonzalez, E. Aguilar, O. Loera, C. Risco, and L. F. Archbald. 2006. Comparison of two estrus-synchronization protocols and timed artificial insemination in dairy cattle. J. Dairy Sci. 89:4567-4572.

Peters, M. W., and J. R. Pursley. 2002. Fertility of lactating dairy cows treated with Ovsynch after presynchronization injections of $\mathrm{PGF}_{2 \alpha}$ and GnRH. J. Dairy Sci. 85:2403-2406.

Peters, M. W., and J. R. Pursley. 2003. Timing of final GnRH of the Ovsynch protocol affects ovulatory follicle size, subsequent luteal function, and fertility in dairy cows. Theriogenology 60:11971204.

Pursley, J. R., M. R. Kosorok, and M. C. Wiltbank. 1997. Reproductive management of lactating dairy cows using synchronization of ovulation. J. Dairy Sci. 80:301-306.

Pursley, J. R., M. O. Mee, and M. C. Wiltbank. 1995. Synchronization of ovulation in dairy cows using $\mathrm{PGF}_{2 \alpha}$ and $\mathrm{GnRH}$. Theriogenology 44:915-923.

Pursley, J. R., R. W. Silcox, and M. C. Wiltbank. 1998. Effect of time of artificial insemination on pregnancy rates, calving rates, pregnancy loss, and gender ratio after synchronization of ovulation in lactating dairy cows. J. Dairy Sci. 81:2139-2144.

Rhodes, F. M., S. McDougall, C. R. Burke, G. A. Verkerk, and K. L. Macmillan. 2003. Invited review: Treatment of cows with an extended postpartum anestrous interval. J. Dairy Sci. 86:1876-1894.

Ryan, D. P., J. A. Galvin, and K. J. O'Farrell. 1999. Comparison of oestrous synchronization regimens for lactating dairy cows. Anim. Reprod. Sci. 56:153-168.

Ryan, D. P., S. Snijders, H. Yaakub, and K. J. O'Farrell. 1995. An evaluation of estrus synchronization programs in reproductive management of dairy herds. J. Anim. Sci. 73:3687-3695.

Santos, J. E. P., W. W. Thatcher, R. C. Chebel, R. L. A. Cerri, and K. N. Galvão. 2004. The effect of embryonic death rates in cattle on the efficacy of estrus synchronization programs. Anim. Reprod. Sci. 82-83:513-535.

Silke, V., M. G. Diskin, D. A. Kenny, M. P. Boland, P. Dillon, J. F. Mee, and J. M. Sreenan. 2002. Extent, pattern and factors associated with late embryonic loss in dairy cows. Anim. Reprod. Sci. 71:1-12.

Stevenson, J. S., D. E. Tenhouse, R. L. Krisher, G. C. Lamb, J. E. Larson, C. R. Dahlen, J. R. Pursley, N. M. Bello, P. M. Fricke, M. C. Wiltbank, D. J. Brusveen, M. Burkhart, R. S. Youngquist, and H. A. Garverick. 2008. Detection of anovulation by heatmount detectors and transrectal ultrasonography before treatment with progesterone in a timed insemination protocol. J. Dairy Sci. 91:2901-2915.

Vasconcelos, J. L. M., R. W. Silcox, G. J. M. Rosa, J. R. Pursley, and M. C. Wiltbank. 1999. Synchronization rate, size of the ovulatory follicle, and pregnancy rate after synchronization of ovulation beginning on different days of the estrous cycle in lactating dairy cows. Theriogenology 52:1067-1078.

Xu, Z. Z., and L. J. Burton. 2000. Estrus synchronization of lactating dairy cows with $\mathrm{GnRH}$, progesterone, and prostaglandin $\mathrm{F}_{2 \alpha}$. J. Dairy Sci. 83:471-476 